\title{
Guillain-Barrè syndrome following COVID-19 vaccine mRNA-1273: a case report
}

\author{
Fabio Giuseppe Masuccio ${ }^{1}\left[\right.$ Cristoforo Comi $^{2,3} \cdot$ Claudio Solaro $^{1}$
}

Received: 29 July 2021 / Accepted: 3 November 2021 / Published online: 12 November 2021

(c) Belgian Neurological Society 2021

Keywords Guillain-Barrè syndrome · COVID-19 vaccine · Vaccination · SARS-CoV-2

\section{Dear Editor}

Vaccination against Severe Acute Respiratory Syndrome Coronavirus-2 (SARS-CoV-2) infection represents one of the most effective measures to contain and reduce the possibility of contracting coronavirus disease (COVID-19) [1]. The mRNA vaccines are useful in preventing the disease and lowering viral load if infected [1]. Thus, an enormous benefit derives from vaccination.

Cases of Guillain-Barrè syndrome (GBS) have been recently described following COVID-19 vaccination, in particular BNT162b2 (Comirnaty ${ }^{\mathrm{TM}} / \mathrm{Pfizer-BioNTech)} \mathrm{[2]}$ and ChAdox 1-S/nCoV-19 (CovishieldTM/Vaxzevria AstraZeneca) [3, 4].

Here we describe a case of GBS following COVID-19 mRNA-1273 vaccine (Moderna ${ }^{\mathrm{TM}}$ ) in an old Caucasian man, affected with Chronic Obstructive Pulmonary Disease and chronic heart failure, in treatment with inhaled budesonide-formoterol and furosemide, bisoprolol, sacubitril-valsartan.

He completed the vaccination cycle on the 30th of April 2021, with progressive lower limbs weakness since the 14th of June, for which he was referred to the local hospital on the 16th of June.

The neurological examination showed a clinical picture of tetraparesis [Medical Research Council (MRC) global upper limb strength 4/5; lower limb strength 3/5], absent

Fabio Giuseppe Masuccio

fgmasuccio@gmail.com

1 Department of Rehabilitation, C.R.R.F. "Mons. L. Novarese", Loc. Trompone SNC, 13040 Moncrivello, Italy

2 Presidio Ospedaliero Sant'Andrea di Vercelli, Corso Abbiate 21, Vercelli, Italy

3 Department of Translational Medicine, University of Eastern Piedmont Amedeo Avogadro School of Medicine, Via Solaroli 17, Novara, Italy deep tendon reflexes and reduced tactile and pain sensitivity, prevalent in the lower limbs.

Vital signs were normal and he did not experience any recent respiratory or gastrointestinal infection. A reverse transcriptase polymerase chain reaction nasopharyngeal swab for SARS-CoV-2 was negative at admission in the hospital.

Brain and spinal cord magnetic resonance imaging did not reveal acute alterations. Cerebrospinal fluid analysis documented albumin-cytological dissociation.

The electrophysiological examination detected mixed axonal and demyelinating features (Table 1). Distal motor latencies and F-waves were augmented in the four limbs, with proximal conduction blocks in the upper limbs. Intravenous immunoglobulins (Ig) were administered ( $35 \mathrm{~g} /$ daily for 5 days) with initial muscular strength amelioration. The patient did not need mechanical ventilation.

IgM and IgG for Epstein-Barr Virus, Cytomegalovirus, Herpes Simplex Virus and Herpes Zoster Virus, HIV, Borrelia Burgdorferi, Chlamidya and Mycoplasma Pneumoniae were negative on both serum and cerebrospinal fluid, while SARS-CoV-2 IgG were present in serum. Also, the determination of antiganglioside antibodies exhibited negative results.

Admitted in rehabilitation on the 30th of June, the patient presented a MRC-sum score of 48 (global limbs strength $4 / 5$ ), GBS-Disability scale $=2$; Barthel Index $=50$, currently undergoing a personalized rehabilitative treatment.

According to clinical features, a subacute GBS might be reasonably hypothesized after the administration of COVID19 mRNA-1273 vaccine second dose, with about 6 weeks elapsing between the vaccination and the symptoms onset.

Cases of GBS have been reported after the first doses of BNT162b2 (ComirnatyTM/Pfizer-BioNTech) [2] and ChAdox 1-S/nCoV-19 (Covishield ${ }^{\mathrm{TM} / V a x z e v r i a}$ Astra-Zeneca) $[3,4]$ vaccines. 
Table 1 Electrophysiological examination of the patient.

\begin{tabular}{|c|c|c|c|c|}
\hline Nerve conductions & Distal latency (ms) & Amplitude (mV) & Conduction velocity (m/s) & F-wave latency (ms) \\
\hline \multicolumn{5}{|l|}{ Motor } \\
\hline \multicolumn{5}{|l|}{ Median nerve } \\
\hline Wrist-abductor pollicis brevis & $\mathrm{L}=4.3 ; \mathrm{R}=6.4$ & $\mathrm{~L}=4.9 ; \mathrm{R}=5.6$ & & \\
\hline Below elbow-wrist & $\mathrm{L}=10.75 ; \mathrm{R}=11.1$ & $\mathrm{~L}=4.2 ; \mathrm{R}=5.9$ & $\mathrm{~L}=32.6 ; \mathrm{R}=48.9$ & $\mathrm{~L}=34.98 ; \mathrm{R}=36.07$ \\
\hline \multicolumn{5}{|l|}{ Ulnar nerve } \\
\hline Wrist-abductor digiti minimi & $\mathrm{L}=2.25 ; \mathrm{R}=2.6$ & $\mathrm{~L}=4.7 ; \mathrm{R}=4.8$ & & \\
\hline Below elbow-wrist & $\mathrm{L}=6.15 ; \mathrm{R}=6.45$ & $\mathrm{~L}=4.8 ; \mathrm{R}=3.5$ & $\mathrm{~L}=46.2 ; \mathrm{R}=57.1$ & \\
\hline Over-below elbow & $\mathrm{L}=9 ; \mathrm{R}=8.75$ & $\mathrm{~L}=3.5 ; \mathrm{R}=2.9$ & $L=45.6 ; R=56.5$ & $\mathrm{~L}=36.23 ; \mathrm{R}=32.93$ \\
\hline \multicolumn{5}{|l|}{ Tibial nerve } \\
\hline Med. Malleolus-abd. hallucis b & $\mathrm{L}=5.65 ; \mathrm{R}=5.35$ & $\mathrm{~L}=2.3 ; \mathrm{R}=1.8$ & & \\
\hline Popliteal fossa-med. malleolus & $\mathrm{L}=15.7 ; \mathrm{R}=22.4$ & $\mathrm{~L}=1.2 ; \mathrm{R}=0.9$ & $\mathrm{~L}=32.9 ; \mathrm{R}=24$ & $\mathrm{~L}=\mathrm{NA} ; \mathrm{R}=48.64$ \\
\hline \multicolumn{5}{|l|}{ Peroneal nerve } \\
\hline Ankle-extensor digit. brevis & $\mathrm{L}=3.9 ; \mathrm{R}=7.7$ & $\mathrm{~L}=0.4 ; \mathrm{R}=0.2$ & & \\
\hline Caput fibulae-ankle & $\mathrm{L}=14.85 ; \mathrm{R}=21.45$ & $\mathrm{~L}=0.2 ; \mathrm{R}=0.0$ & $\mathrm{~L}=32.9 ; \mathrm{R}=26.2$ & \\
\hline \multicolumn{5}{|l|}{ Antidromic sensory } \\
\hline \multicolumn{5}{|l|}{ Median nerve } \\
\hline Wrist-II finger & $\mathrm{L}=4.2 ; \mathrm{R}=4.35$ & ${ }^{\mathrm{a}} \mathrm{L}=3.3 ; \mathrm{R}=2.2$ & $\mathrm{~L}=32.1 ; \mathrm{R}=32.2$ & \\
\hline \multicolumn{5}{|l|}{ Ulnar nerve } \\
\hline Wrist-IV finger & $\mathrm{L}=3.45 ; \mathrm{R}=2.8$ & ${ }^{\mathrm{a}} \mathrm{L}=3.8 ; \mathrm{R}=5.0$ & $\mathrm{~L}=31.9 ; \mathrm{R}=42.9$ & \\
\hline \multicolumn{5}{|l|}{ Radial nerve } \\
\hline Wrist-I finger & $\mathrm{L}=\mathrm{NA} ; \mathrm{R}=3.05$ & ${ }^{\mathrm{a}} \mathrm{L}=\mathrm{NA} ; \mathrm{R}=4.1$ & $\mathrm{~L}=\mathrm{NA} ; \mathrm{R}=25.5$ & \\
\hline \multicolumn{5}{|l|}{ Sural nerve } \\
\hline Calf-Lat. malleolus & $\mathrm{L}=3.8 ; \mathrm{R}=2.65$ & ${ }^{\mathrm{a}} \mathrm{L}=4.1 ; \mathrm{R}=3.1$ & $\mathrm{~L}=42.1 ; \mathrm{R}=45.3$ & \\
\hline
\end{tabular}

$L$ left, $R$ right, $A$ absent, $N A$ not available

${ }^{\mathrm{a}} \mu \mathrm{V}$

Our patient experienced the beginning of GBS symptoms after completing the vaccination cycle. When considering the cases after ChAdox $1-\mathrm{S} / \mathrm{nCoV}-19$ vaccination, which needed mechanical ventilation for the most part [3, 4], in our case (and in the case of GBS after BNT162b2 administration [2]), a longer time of symptoms presentation and a milder clinical picture were recognizable.

With this respect, we can speculate that a late autoimmunity reaction might have occurred with a molecular mimicry mechanism [5], probably after seroconversion. Accordingly, in our patient, SARS-CoV-2 IgG antibodies were detected in the serum, feasibly responsible of the onset of the molecular mimicry process [5], although antiganglioside antibodies were not found. However, this hypothesis cannot be confirmed due to the nature of this case report.

GBS is a rare and sometimes disabling disease. Despite the controversial link between this neurologic pathology and SARS-CoV-2 vaccination [5], the risk-benefit ratio clearly recommends the vaccination due to its efficacy in reducing the morbidity and mortality for COVID-19 [1]. The first report on the possible association between GBS and vaccination was in 1976 during the mass vaccination campaign against Swine Influenza in the USA, with an eightfold rise in the incidence of GBS in those vaccinated (4.9-5.9/1,000,000) [5]. However, further studies trying to assess this relation in other type of vaccines revealed inconsistent results. In addition, it must be considered that the risk of having GBS is higher when contracting COVID-19 than after vaccination, as it is for influenza [5].

Therefore, the enforcement of vaccination programs should be accompanied by a proper surveillance after administration. This might enhance GBS prompt diagnosis, also allowing to monitor for long-term adverse effects.

Author contributions All authors contributed equally to this work.

Funding Not applicable.

Data availability Anonymized data and material regarding this case report not included in the manuscript are available on request to the corresponding author by any qualified investigator. 


\section{Declarations}

Conflict of interest The authors declare no conflict of interest relevant to this paper.

Consent to publication Written informed consent was collected from the patient for the inclusion of anonymized clinical data in a scientific publication, in agreement with the Declaration of Helsinki.

\section{References}

1. Thompson MG, Burgess JL, Naleway AL et al (2021) Prevention and attenuation of COVID-19 with the BNT162b2 and mRNA1273 vaccines. N Engl J Med. https://doi.org/10.1056/NEJMo a2107058

2. Waheed S, Bayas A, Hindi F et al (2021) Neurological complications of COVID-19: Guillain-Barre syndrome following Pfizer
COVID-19 vaccine. Cureus 13:2-5. https://doi.org/10.7759/ cureus. 13426

3. Marammatom BV, Krishnan P, Paul R et al (2021) Guillain-Barré syndrome following ChAdOx1-S/nCoV-19 vaccine. Ann Neurol 2:1-3. https://doi.org/10.1002/ana.26143

4. Hasan T, Khan M, Khan F, Hamza G (2021) Case of GuillainBarré syndrome following COVID-19 vaccine. BMJ Case Rep 14:e243629. https://doi.org/10.1136/bcr-2021-243629

5. Koike H, Chiba A, Katsuno M (2021) Emerging infection, vaccination, and Guillain-Barré syndrome: a review. Neurol Ther. https://doi.org/10.1007/s40120-021-00261-4

Publisher's Note Springer Nature remains neutral with regard to jurisdictional claims in published maps and institutional affiliations. 